\title{
CONGENITAL DISLOCATION OF THE KNEE - APROPOS OF TWO CASES
}

\author{
Camelia Vreme' ${ }^{1}$ Laura Popa ${ }^{2}$, Ștefana Carp², Eduard Liciu², \\ Stefan-Traian Gavriliu' ${ }^{1}$, Costel Vlad ${ }^{2}$
}

\section{Abstract}

Congenital dislocation of the knee $(\mathrm{CDK})$ is a relatively rare disorder. The deformity may be isolated or part of a syndromic condition. The purpose of this paper is to present the experience with two cases of $\mathrm{CDK}$, one of them being complicated by a simultaneous unilateral hip dislocation.

We present two cases of CDK treated surgically by our team. The first case is an 11 months old girl with bilateral CDK associated with bilateral congenital clubfoot and congenital dislocation of the right hip. The second case is a 6 months old boy having multiple conditions: CDK, atrial septal defect, ventricular septal defect, left ventricular hypertrophy, hypoacusis, postaxial hexadactyly of the right foot.

For CDK, we performed in both cases V-Y quadricepsplasty, anterior capsule release and spica cast immobilisation with 45 degrees of flexion of the knees for 4 weeks. We performed also surgical procedures for the associated deformities.

The results are very good in both cases. The patients are independent walkers having a normal range of physical activities. The knees are stable; the flexion is about 120 degrees in the first case and at 110 degrees in the second case.

The treatment of CDK is challenging and should be adapted to the particular conditions of the patient: age, state of the soft parts, associated deformities. Establishing the optimum equilibrium between flexion and extension should prevail over the ambition to obtain full flexion of the knee.

Keywords: congenital dislocation of the knee, V-Y quadriceps-plasty, surgical treatment

\section{Introduction}

Congenital dislocation of the knee is a rare [1] and debilitating disorder if left untreated. The image of the newborn is striking, the lower limbs being positioned in various degrees of hyper-extension and the tibia displaced in front of the femur in most cases.

The deformity may be unique or part of a syndromic condition [2]. The fundamental pathologic alterations consist of quadriceps tendon shortening, tight suprapatellar bursa, anterior capsule retraction [3,4]. Valgus deformity and posterior capsule excess are secondary to the other pathologic alteration.

Many surgical options are available according to the degree of deformity and age of the patient [5-8]. The variability of the approaches is the indicator that a universal solution is not yet accepted.

The purpose of this paper is to present our experience with two cases of CDK, one of them being complicated by a simultaneous unilateral hip dislocation.

\section{Materials and Methods \\ We present two cases of CDK treated surgically by our} team.

\section{Case one}

The first case is an 11 months old girl addressed to our service for a bony protuberance at the posterior aspect of both knees and bilateral clubfoot with major equinus component and mild forefoot adduction (Fig. 1A). During the first eleven months of life the knees and feet were stretched by the parents, under no medical supervision, in order to correct the hyperextension of the knees present at birth. Apparently, the knees were well aligned despite lack of flexion in both knees (Fig. 1B). Clinical examination and $\mathrm{X}$-ray revealed the anterior dislocation of both knees with compensatory flexion deformity of both tibias (Fig. 2A). The right hip was dislocated (Fig. 2B).

The treatment we proposed and performed was bilateral, V-Y quadriceps-plasty, anterior capsule release, Achilles tenotomy, right hip closed reduction, spica cast immobilisation with 90 degrees of flexion and 60 degrees of abduction of the hip and 45 degrees of flexion of the knees for 4 weeks. Duration of surgery was three hours and the blood loss was minimal. The Pavlik harness was worn 6 months after cast removal. Intensive rehabilitation program took place after cast removal.

${ }^{1}$ Paediatric Orthopaedic Department, Emergency Hospital for Children MS Curie

${ }^{2}$ Paediatric Orthopaedic Department, Clinical Hospital for Children Dr. Victor Gomoiu

E-mail: camelia1990_camelia1990@yahoo.com,1.lauradobre@gmail.com, stefana.carp@gmail.com,

liciueduard@gmail.com, banteo@gmail.com,costelvlad.cv@gmail.com 


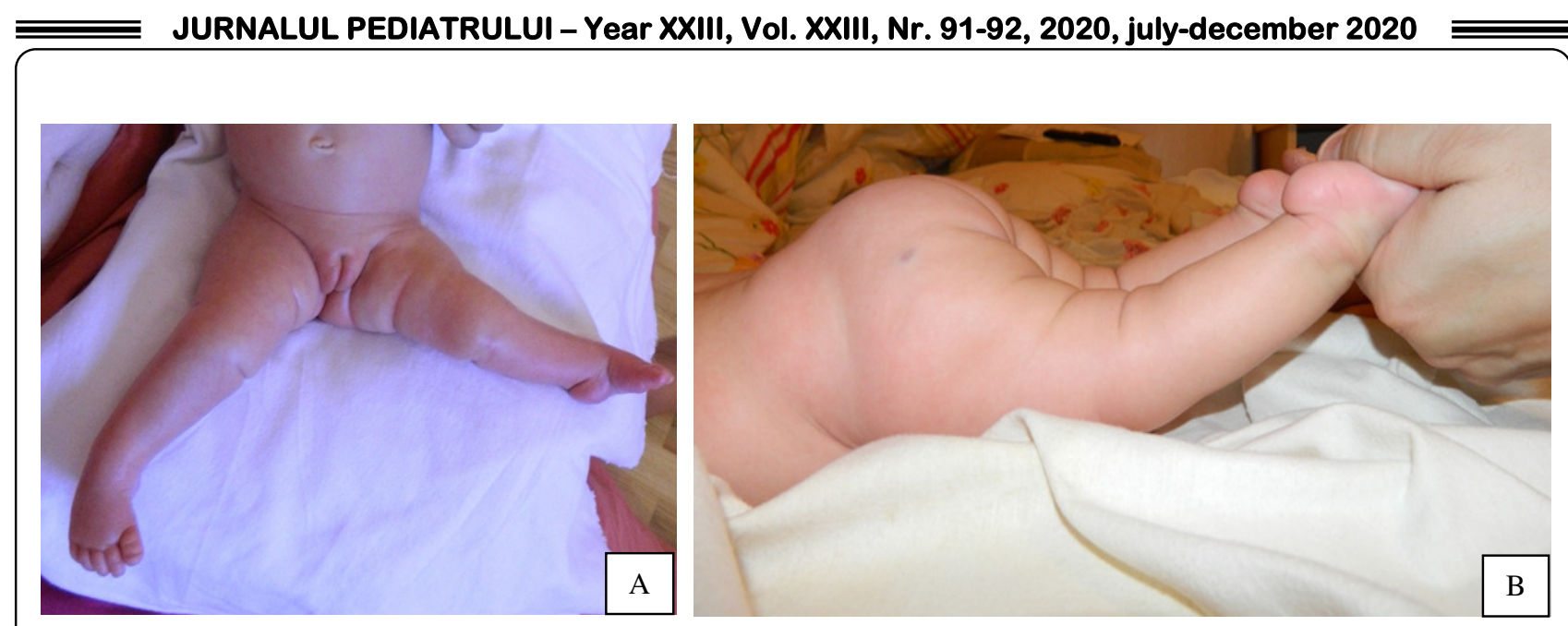

Figure 1: A - Case one, clinical aspect at one month of age. B - Case one, clinical aspect at first presentation in our department.
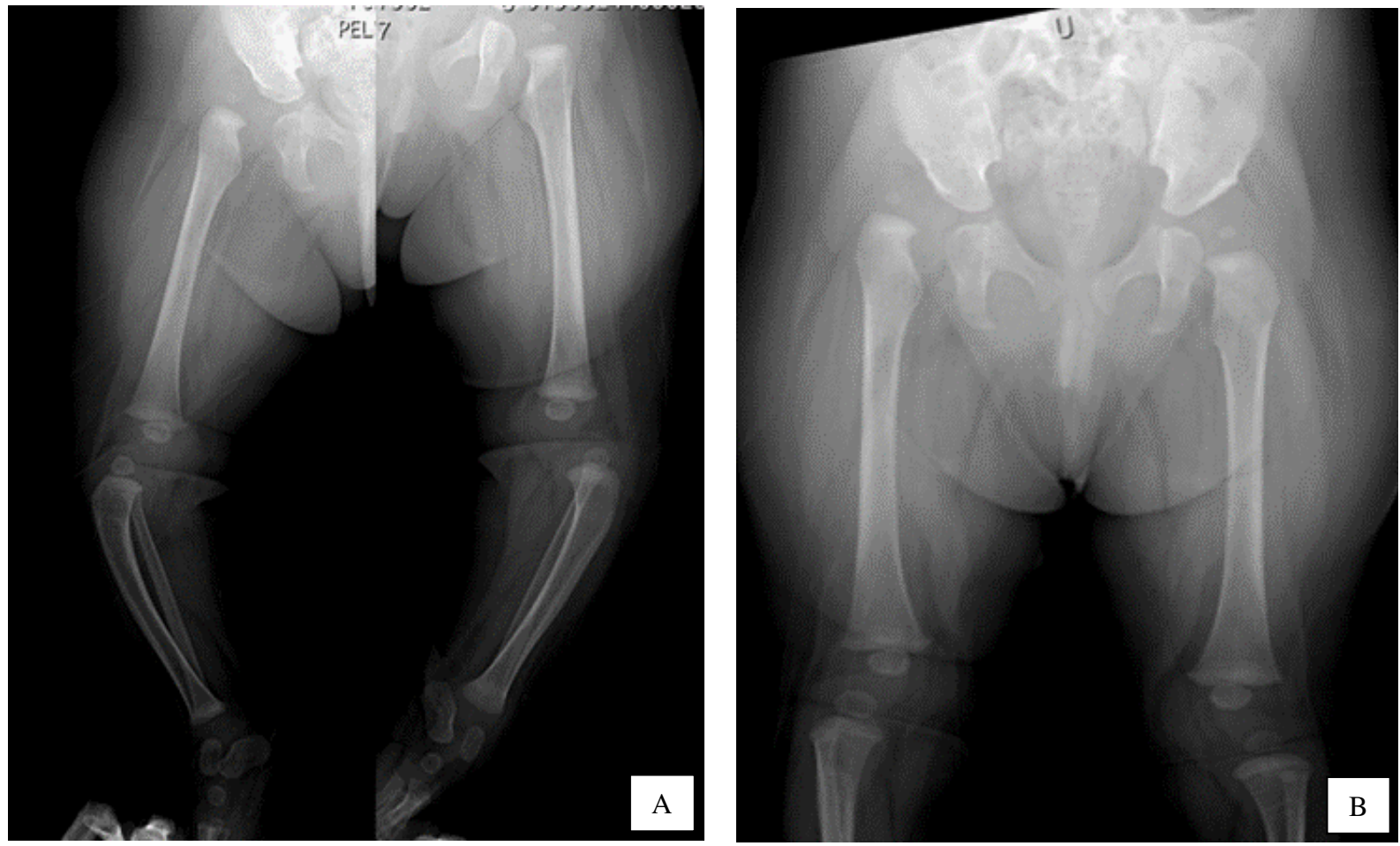

Figure 2. A - Case one, X-ray image of lower limb in lateral view, the bowing of both tibias in sagital plane compensate the knee dislocation. B - Case one, X-ray exam of the right dislocated hip.

\section{Case two}

The second case is a 6 months old boy having multiple conditions: bilateral CDK, atrial septal defect, ventricular septal defect, left ventricular hypertrophy, hypoacusis, postaxial hexadactyly of the right foot (Fig. 3A, Fig 3B). We proposed and performed the V-Y quadriceps-plasty
(Fig. 4A, Fig. 4B), anterior capsule release and resection of the sixth toe followed by spica cast immobilisation for 4 weeks). After this period, the cast was changed with anterior plaster splint for another 4 weeks (Fig. 5A, Fig 5B. The intensive rehabilitation program was started after cast removal. 

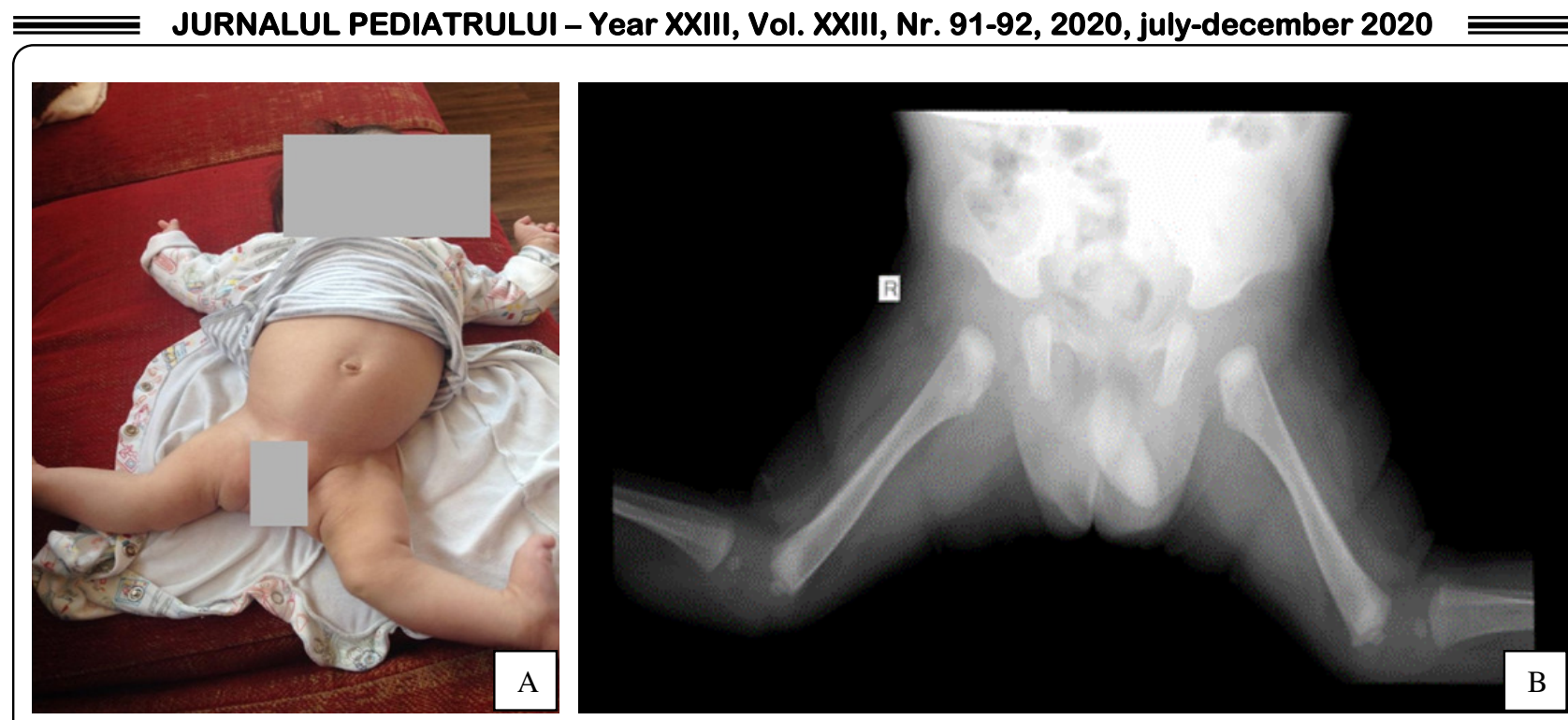

Figure 3. A - Case two, clinical picture at 6 month of age. B - Case two, lateral view on X-ray image of dislocated knees.
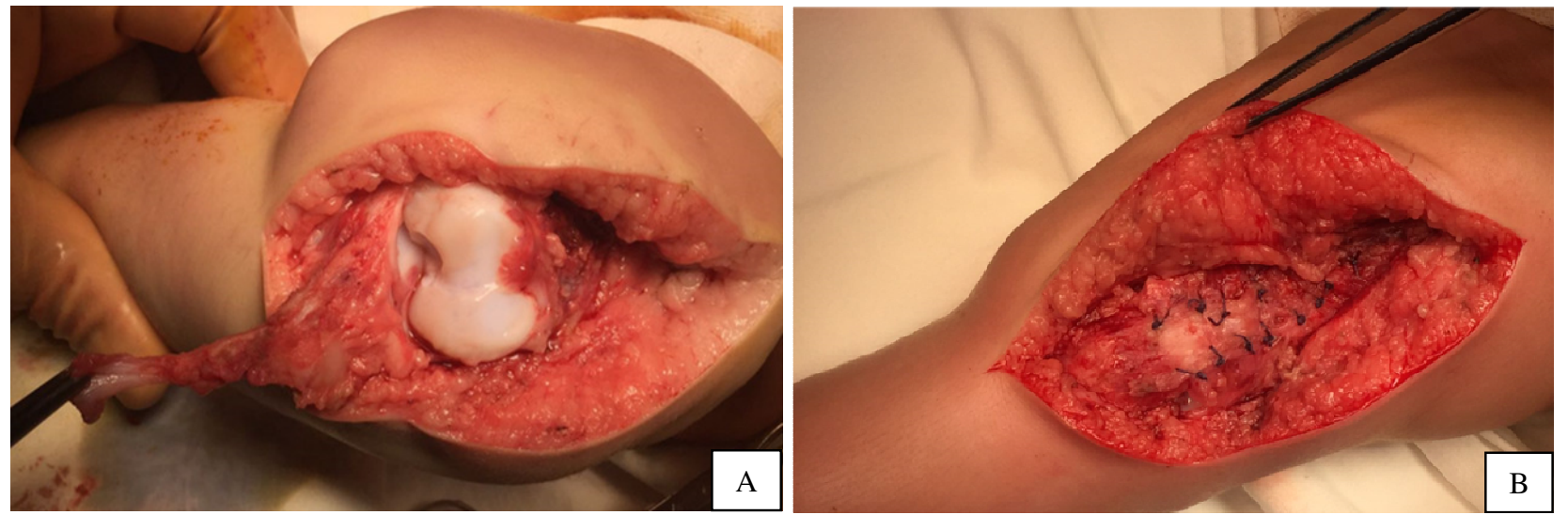

Figure 4. A - Case two, intraoperative image of the knee after full dissection, before the quadriceps stiching. B - Case two, intraoperative aspect after the V-Y stiching of the quadriceps tendon.
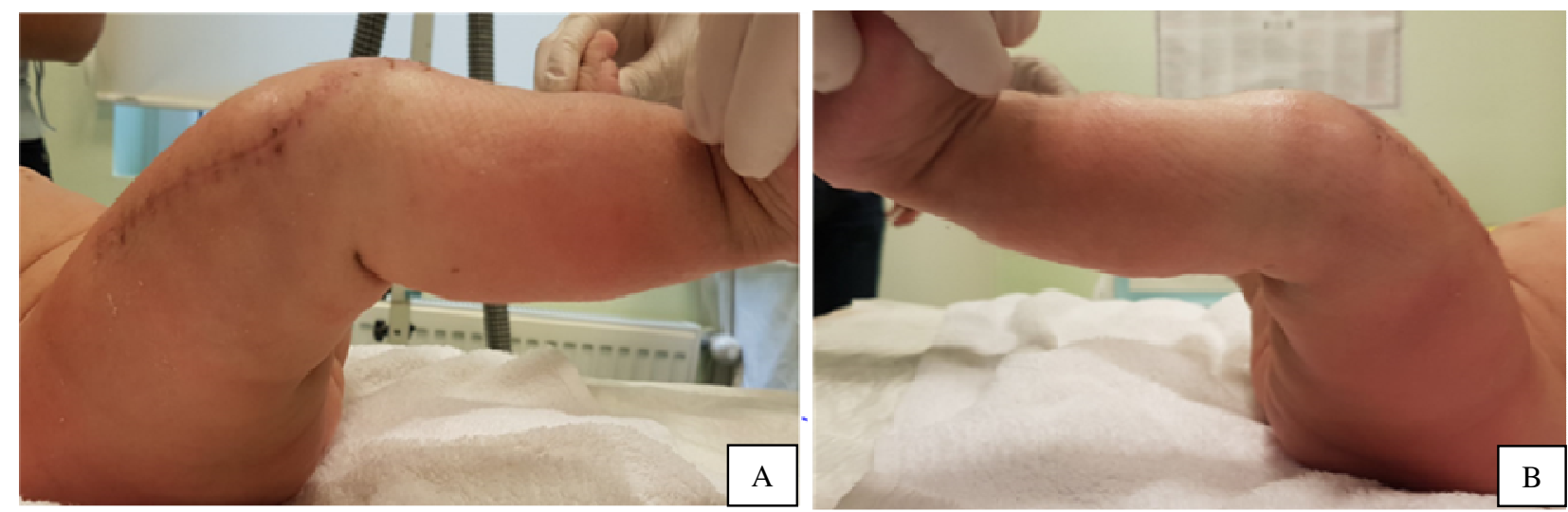

Figure 5. A - Case two, right knee immediately after cast removal. B - Case two, left knee immediately after cast removal. 


\section{Results}

\section{Case one}

The evolution was very good. The hip remained stable and the acetabular dysplasia improved slowly. The need for a pelvic osteotomy is not completely ruled out but the MRI exam performed at 4 years of age revealed an excellent potential of ossification of the acetabular rim (Fig. 6A, Fig. 6B).

The knee flexion is at 120 degrees, the knees are stable (Fig. 7A, Fig. 7B). Mild adductus of forefeet still persist.
The patient is an independent walker having a normal range of physical activities.

The tibial incurvation regressed spontaneously; during the 5 years postoperatively both tibias achieved almost normal anatomical axis.

\section{Case two}

At one year of age the boy became independent walker with good range of motion. He is still improving the knees flexion. At last follow up the knees flexion was about 110 degrees (Fig. 8A, Fig. 8B).
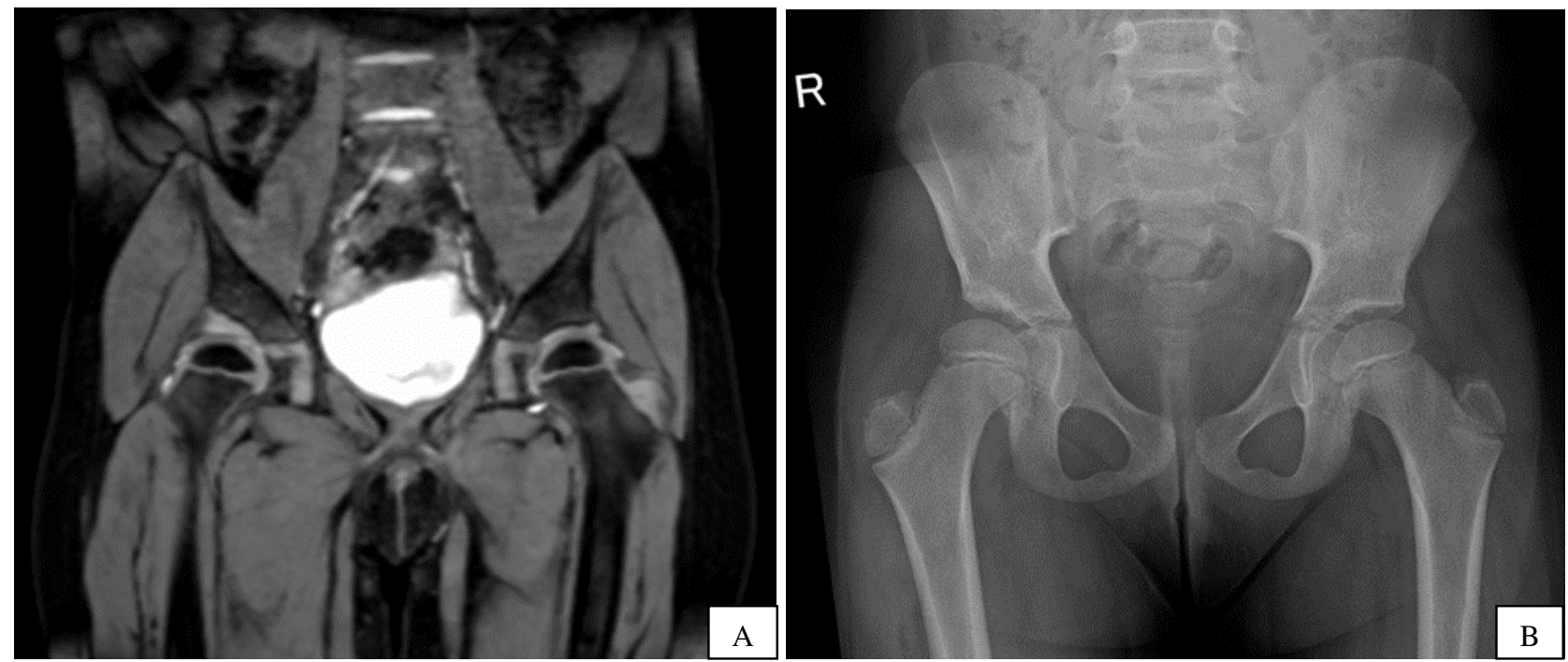

Figure 6. A - Case one, MRI aspect of the hips, at the age of 4 years, the right hip is displastic but the cartilaginous part of the acetabulum covers perfectly the femoral head. B - Case one, X-ray image of the pelvis on A-P view, at the age of 6 years, the right hip is slightly dysplastic but the Wiberg angle is positive, a surgical procedure to improve the right hip coverage may be required in the future.
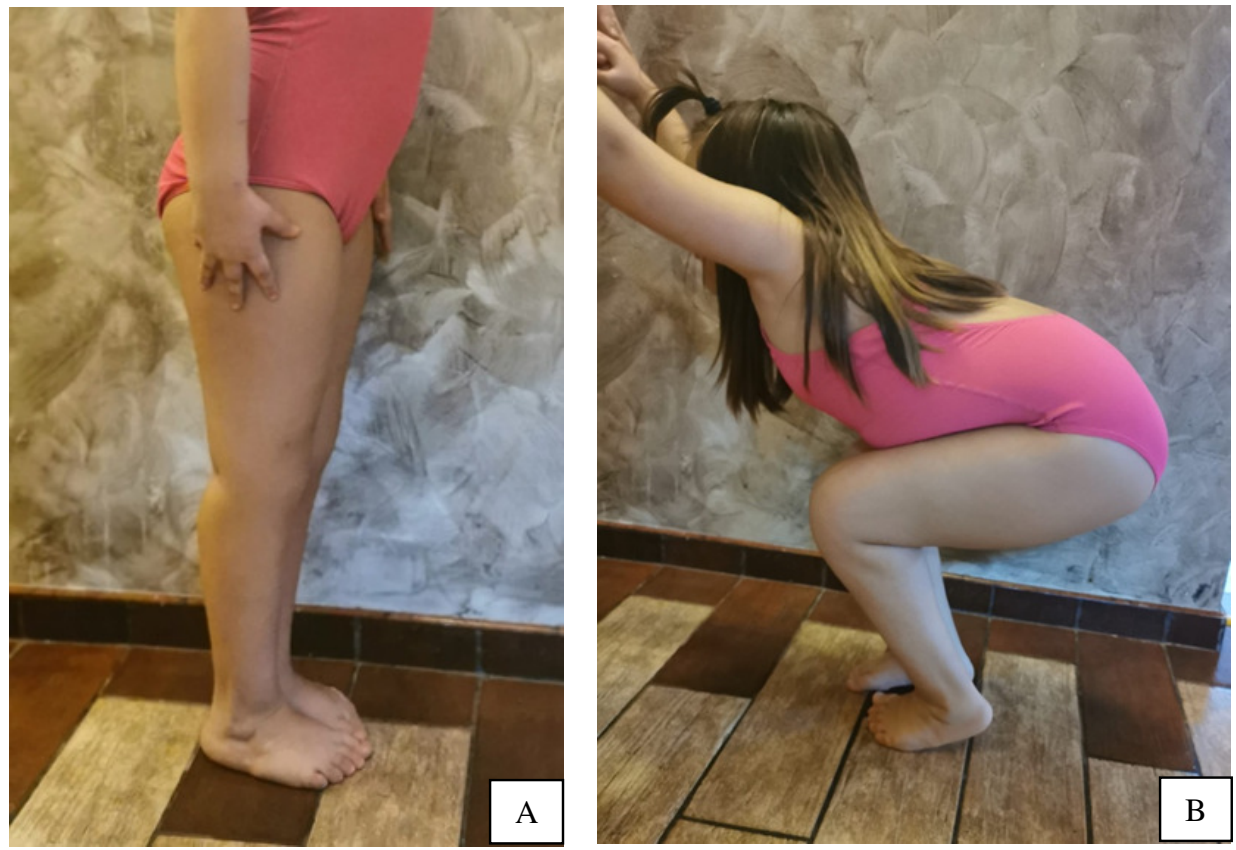

Figure 7. A,B - Case one, clinical aspect of the knees at 7 years of age. 


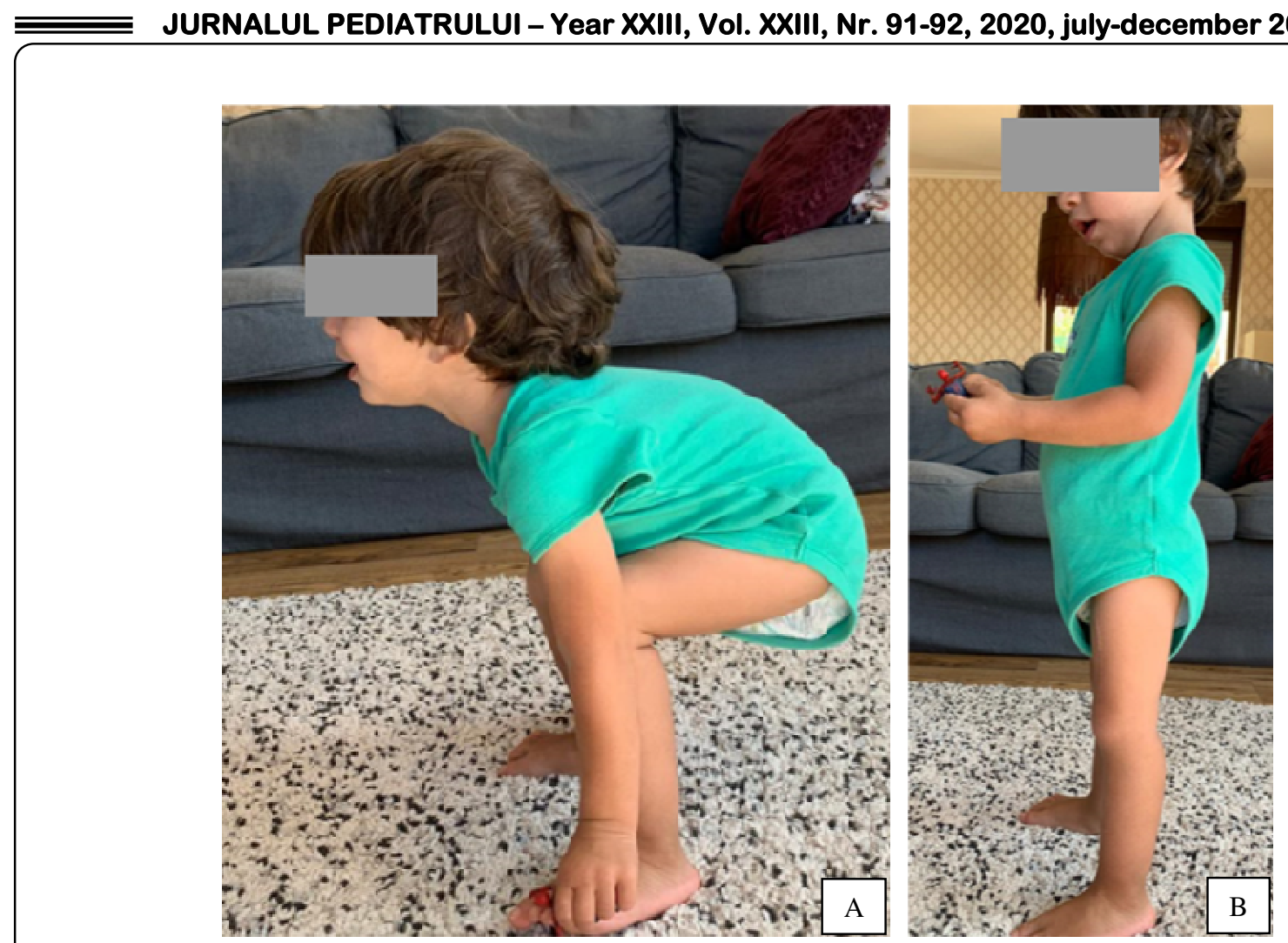

Figure 8. A,B - Case two at 2 years of follow-up.

\section{Discussion}

Ideally, the diagnostic of congenital dislocation of the knee should be made during the intrauterine life [9] for at least two reasons: to be prepared to apply promptly orthopaedic treatment in mild cases or to prepare the parents for a surgery with good but not perfect results at the end of treatment.

When diagnosed early and the dislocation is reducible [10] the CDK may be managed with serial casting and in some cases with soft parts release. Spontaneous reduction was described [11]. When dislocation is irreducible, the open extensive surgery is mandatory.

Different opinions exist regarding the best approach to restore the knee flexion. Special concerns exist when a simultaneous hip dislocation need to be treated [7]. Johnston et al. propose a simultaneous acute femoral shortening in order to lower the tension generated in the retracted soft tissues secondary to the reduction of both dislocations.

Quadriceps lengthening is proposed by some authors, in $\mathrm{Z}$ - shape or V-Y fashion [12]. One concern of this soft tissue release is the weakening of the quadriceps tendon and secondary need for surgery. Söyüncü et al. [12] described a reinforcement procedure of quadriceps tendon with Achilles tendon allograft in cases of quadriceps lengthening failure. The main issue with the lengthening procedure is a massive fibrosis which encounters the quadriceps tendon. Creating good enough flaps in order to provide a strong connection between the quadriceps muscle and patella may be technically difficult. Having access to a tissue bank may be reassuring for the surgeon.

A logical approach to the technical difficulties in these cases is the femoral acute shortening proposed by Johnston et al. [7]. In the comprehensive approach proposed by Johnston we emphasise the need to address both dislocations in the same time; on the other hand, the anterior cruciate ligament reconstruction is advised in order to correct the instability of the knee. In some cases, an osteotomy of the tibia to correct flexion deformity may be required.

In the first case we presented the simultaneous dislocation of the hip who was treated orthopedically, maybe the general laxity of the patient helped to obtain and maintain the hip reduction free of complications. Also, the presence of clubfoot deformity made the rehabilitation treatment more difficult. A good result is characterized by a stable knee and at least 90 degrees of flexion. One of the recommendations concerning the postoperative immobilisation of the knee is to keep flexion below 60 degrees, otherwise the extension recovery will be incomplete or extremely difficult. Having to improve the knee flexion is the preferable attitude.

The hip dysplasia present in the first case may be the subject of future surgery. We postponed a procedure to address the hip dysplasia (Fig. 6A) based on MRI exam revealing a cartilaginous part of the acetabular rim which would provide a good acetabular coverage after full ossification, 
Spontaneous reestablishment of anatomical axis of both tibias was observed and this was presumed preoperatively. Maybe the elasticity of the joints allowed us to obtain a good hip reduction without complications or open surgery.

The second case had a good result, with 110 degrees of flexion. The boy is walking independently. The knees are stable.

\section{Conclusions}

CDK is a rare and challenging condition to treat, especially when other dislocations are associated. The treatment should be tailored to the particular conditions of the patient: age, state of the soft tissues, associated deformities. Attention to be paid to the temptation to obtain full flexion with the price of never regaining full extension.

\section{References}

1. Shastri NJ, Winners O. Picture of the month. Congenital Dislocation of the Knee. Arch Pediatr Adolesc Med. 2008;162(8):787. Epub 2008/08/06. doi: 10.1001/archpedi.162.8.787. PubMed PMID: 18678813.

2. Bhatia RK, Pyman J, Gargan MF, Witherow PJ. Cases of congenital dislocation of the knee (CDK) not associated with clubfoot, arthrogryposis multiplex congenita, and Larsen's syndrome can be treated conservatively. J Pediatr Orthop. 1998;18(2):273-4. Epub 1998/04/08. doi: 10.1097/00004694-19980300000030. PubMed PMID: 9531418.

3. Ooishi T, Sugioka Y, Matsumoto S, Fujii T. Congenital dislocation of the knee. Its pathologic features and treatment. Clin Orthop Relat Res. 1993(287):187-92. Epub 1993/02/01. PubMed PMID: 8448939.

4. Uhthoff HK, Ogata S. Early intrauterine presence of congenital dislocation of the knee. J Pediatr Orthop. 1994;14(2):254-7. Epub 1994/03/01. doi: 10.1097/01241398-199403000-00023. PubMed PMID: 8188844.

5. B KA, Singh KA, Shah H. Surgical management of the congenital dislocation of the knee and hip in children presented after six months of age. Int Orthop. 2020;44(12):2635-44. Epub 2020/08/11. doi: 10.1007/s00264-020-04759-8. PubMed PMID: 32772317 ; PMCID: PMC7679307.

6. Klein C, Bulaid Y, Deroussen F, Plancq MC, Printemps $\mathrm{C}$, Gouron R. Congenital dislocation of the knee in a three-year-old-child with Larsen syndrome: Treatment with a hexapod-type external fixator. Knee. 2018;25(5):966-71. Epub 2018/08/17. doi: 10.1016/j.knee.2018.07.006. PubMed PMID: 30111500 .
7. Johnston CE, 2nd. Simultaneous open reduction of ipsilateral congenital dislocation of the hip and knee assisted by femoral diaphyseal shortening. J Pediatr Orthop. 2011;31(7):732-40. Epub 2011/09/20. doi: 10.1097/BPO.0b013e31822f1b24. PubMed PMID: 21926869.

8. Tercier S, Shah H, Joseph B. Quadricepsplasty for congenital dislocation of the knee and congenital quadriceps contracture. J Child Orthop. 2012;6(5):397410. Epub 2013/10/02. doi: 10.1007/s11832-012-04378. PubMed PMID: 24082955; PMCID: PMC3468735.

9. Elchalal U, Ben Itzhak I, Ben-Meir G, Zalel Y. Antenatal diagnosis of congenital dislocation of the knee: a case report. Am J Perinatol. 1993;10(3):194-6. Epub 1993/05/01. doi: 10.1055/s-2007-994717. PubMed PMID: 8517894

10. Abdelaziz TH, Samir S. Congenital dislocation of the knee: a protocol for management based on degree of knee flexion. J Child Orthop. 2011;5(2):143-9. Epub 2012/04/03. doi: 10.1007/s11832-011-0333-7. PubMed PMID: 22468158; PMCID: PMC3058203.

11. Haga N, Nakamura S, Sakaguchi R, Yanagisako $Y$, Taniguchi K, Iwaya T. Congenital dislocation of the knee reduced spontaneously or with minimal treatment. J Pediatr Orthop. 1997;17(1):59-62. Epub 1997/01/01. PubMed PMID: 8989703.

12. Söyüncü Y, Mihçi E, Ozcanli H, Ozenci M, Akyildiz F, Aydin AT. Reconstruction of quadriceps tendon with Achilles tendon allograft in older children with congenital dislocation of the knee. Knee Surg Sports Traumatol Arthrosc. 2006;14(11):1171-5. Epub 2006/06/08. doi: 10.1007/s00167-006-0083-0. PubMed PMID: 16758235.

Correspondence to:

Costel VLAD,

Paediatric Orthopaedic Department,

Clinical Hospital for Children Dr. Victor Gomoiu,

Bd. Basarabia 21, Sector 2 Bucharest,

Tel. 0040314136700

E-mail: costelvlad.cv@gmail.com 